\title{
MORFOLOGÍA DE EMBRIONES Y PLÁNTULAS DE ESPECIES LEÑOSAS DEL NORDESTE ARGENTINO
}

\author{
por MARÍA C. FRANCESCHINI'
}

\section{Summary}

\begin{abstract}
In this paper embryos and seedlings of six native woody species of Northeast of Argentina are studied: Chrysophyllum marginatum (Hook. et Arn.) Radlk. subsp. marginatum (Sapotaceae), Eugenia uniflora L., Hexachlamys edulis (O. Berg) Kausel et D. Legrand (Myrtaceae), Polygala albicans (A.W. Benn.) Grondona (Polygalaceae), Sapium haematospermun Müll. Arg. and Sebastiania brasiliensis Spreng. (Euphorbiaceae). Descriptions and illustrations of seeds, embryos, germination and seedlings are given.
\end{abstract}

Key words: embryos, germination, seedlings, woody species, Argentina

Palabras clave: embriones, germinación, plántulas, especies leñosas, Argentina

\section{Introducción}

En muchas especies leñosas las hojas de la plántula difieren notablemente de las de la planta adulta; en estos casos, la identificación de una especie que se encuentra en las primeras etapas de su crecimiento se puede tornar dificultosa. El estudio de la plántula no puede separarse de la interpretación de la morfología del embrión y del proceso de germinación. Es importante también considerar la morfología de las semillas, dado que en muchas especies la cubierta seminal permanece unida a los cotiledones después de que éstos se despliegan.

Los trabajos sobre germinación y morfología de plántulas de especies nativas de nuestro país son en general escasos (Bravo, 1978; Gartland et al., 1990 y 1991; Orfila, 1995).

El presente trabajo tiene como objetivo principal describir el tipo de germinación, las características más notables de la semilla y del embrión y los distintos estadios de plántula de seis especies leñosas nativas de bosques del

\footnotetext{
${ }^{1}$ Becaria de la SGCyT-UNNE. Instituto de Botánica del Nordeste, Casilla de Correo 209, 3400 Coorrientes, Argentina.
}

nordeste argentino: Chrysophyllum marginatum (Hook. et Arn.) Radlk. subsp. marginatum (Sapotaceae), Eugenia uniflora L., Hexachlamys edulis (O. Berg) Kausel et D. Legrand (Myrtaceae), Polygala albicans (A.W. Benn.) Grondona (Polygalaceae), Sapium haematospermun Müll. Arg. y Sebastiania brasiliensis Spreng. (Euphorbiaceae).

\section{Materiales y métodos}

La extracción de las semillas se realizó manualmente. En los casos en que fue necesario, se aplicaron tratamientos de escarificación mecánica y química. Las semillas se secaron al aire libre.

Para la germinación se colocaron 100 semillas por especie, sobre una base de papel de filtro y algodón, en cajas de plástico transparente.

Las plántulas se transplantaron en macetas en una mezcla de tierra y perlita. El material fue regado con fungicida y cultivado a temperatura ambiente. Se registró el poder germinativo (PG) de cada especie, tomándose como referencia 7 días.

Para conocer la naturaleza de las sustancias de reserva de la semilla se usó Sudán IV (solu- 
ción alcohólica saturada) y Lugol (D’Ambrogio de Argüeso, 1986); se realizó diafanización de los cotiledones (Dizeo de Strittmatter, 1973). Para la descripción de la venación se siguió la terminología de Hickey (1974) y para la del embrión la de Martin (Duke, 1969).

Los distintos estadios fueron descriptos y dibujados, utilizando un microscopio estereoscópico Wild M5 y su respectiva cámara clara. Sólo con fines descriptivos, se considera como "plántula" al estadio en el cual ya han aparecido por lo menos los dos primeros nomofilos.

Se recolectaron fru tos y se prepararon ejemplares testigos. También se conservaron ejemplares de distintos estadios de las plántulas estudiadas.

Chrysophyllum marginatum subsp. marginatum: ARGENTINA, Prov. Corrientes, Dep. San Cosme, Paso de la Patria, 2/11/98, Franceschini 9 (CTES).

Eugenia uniflora: ARGENTINA, Prov. Corrientes, Dep. San Cosme, camino a Pto. González, $12 /$ 10/98, Franceschini 13 (CTES).

Hexachlamys edulis: ARGENTINA, Prov. Corrientes, Dep. San Cosme, Paso de la Patria, 11/10/98, Franceschini 11 (CTES).

Polygala albicans: ARGENTINA, Prov. Corrientes, Dep. Capital, Molina Punta, 15/12/99, Franceschini 40 (CTES).

Sapium haematospermun: ARGENTINA, Prov. Formosa, Dep. Patiño, Gral. Güemes, 11/01/99, Franceschini 22 (CTES).

Sebastiania brasiliensis: ARGENTINA, Prov. Corrientes, Dep. Capital, Molina Punta, 6/3/97, Franceschini y Tressens 3 (CTES).

\section{Resultados}

\section{Chrysophyllum marginatum (Fig. 1)}

Semilla: 7-9 mm long. x 4-4,5 mm lat., elíptica, endospermada; cubierta seminal de consistencia córnea, superficie pulida, castaña con máculas grisáceas y cicatriz basilar blanquecina (Fig. 1, A y B). Endosperma carnoso, blanquecino, persistente durante la germinación tornándose verde muy pálido en la zona libre de la cubierta seminal.

Las pruebas de endosperma dieron positivo al test de Sudán IV para grasas y aceites y negativo con Lugol para hidratos de carbono.
Embrión: 5-6 mm long. x $4 \mathrm{~mm}$ lat., axial, foliar, espatulado, glabro, níveo; eje embrionario 1-2 mm long. x $1 \mathrm{~mm}$ lat., cilíndrico; $\mathrm{CO}-$ tiledones 4-5 mm long. $\times 4 \mathrm{~mm}$ lat., latiovados, ápice obtuso, base obtusa, margen entero (Fig. 1, c).

Germinación y crecimiento: epigea, fanerocotilar; PG $10 \%$.

1ra. semana: la ruptura de la cubierta seminal se inicia en la cicatriz basilar, emergiendo primero la radícula (Fig. 1, D).

2da. semana: se observa el hipocótilo que junto con la raíz primaria puede llegar a medir hasta $2 \mathrm{~cm}$ long., de color verde claro en la parte superior y blanco hacia la raíz. El suculento endosperma cubre completamente los cotiledones (Fig. 1, E).

3ra. semana: $20 \%$ de semillas germinadas. Los cotiledones se despliegan y enverdecen, la cubierta seminal y una delgada capa de endosperma permanecen adheridos a ellos. El eje hipocótilo-raíz puede llegar a medir desde 4,7-6,2 cm long. (Fig. 1, F).

4ta. semana: $28 \%$ de semillas germinadas, la cubierta seminal se desprende de los cotiledones llevando consigo la delgada capa de endosperma.

5ta. semana: la plántula llega a medir 6-9 $\mathrm{cm}$ long. Una vez desplegados los cotiledones el ritmo de crecimiento disminuye considerablemente (Fig. 1, G).

8-10ma. semana: se evidencian el epicótilo y dos nomofilos.

Plántula (Fig. 1, H): látex blanco. Hipocótilo glabro, castaño, con cuatro costillas membranáceas que lo recorren siguiendo un patrón helicoidal. Epicótilo cilíndrico, verde claro, con pelos malpighiáceos. Cotiledones opuestos, con pecíolo de 2-2,5 mm long., cara adaxial levemente acanalada, cara abaxial convexa; lámina de 1,3-1,5 cm long. x 0,8-1 cm lat., latielíptica, cartácea, glabra, de color verde profundo en la cara adaxial y verde claro en la abaxial; ápice obtuso, base obtusa, en algunos casos aguda; margen entero. Nomofilos simples, subopuestos a alternos, con pelos malpighiáceos en el hipofilo; pecíolo de 1-1,5 mm long., glabro; lámina de 9-10 mm long. $x$ 3-5 mm lat., obovada o elíptica, cartácea, ápice 


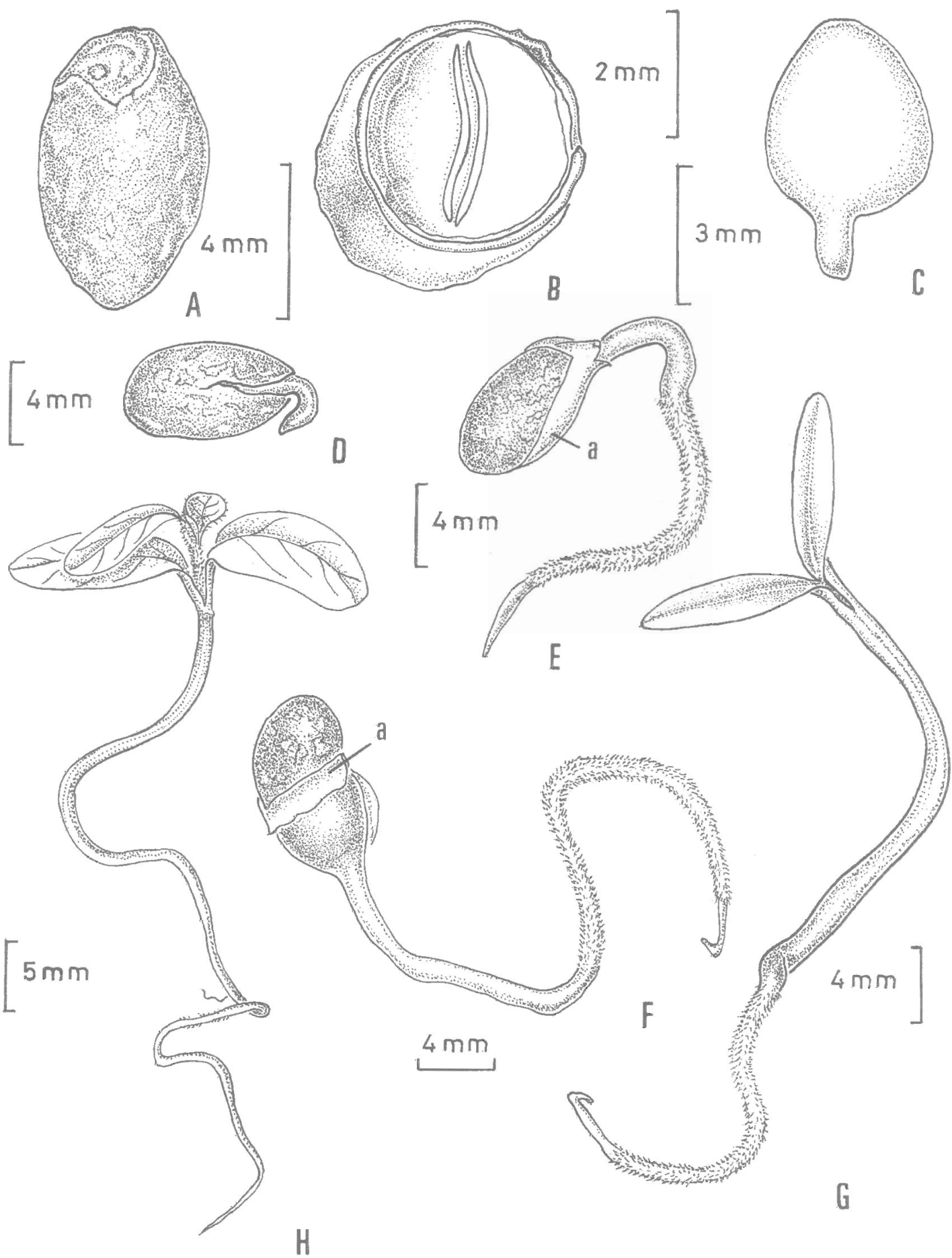

Fig. 1. Chrysophyllum marginatum. A: semilla; B: transcorte de la semilla; C: embrión; D-H: germinación y desarrollo de la plántula; D: 1a. semana; E: 2a. semana; F: 3a. semana; G: 5a. semana; H: plántula. a: endosperma (Franceschini 9). 


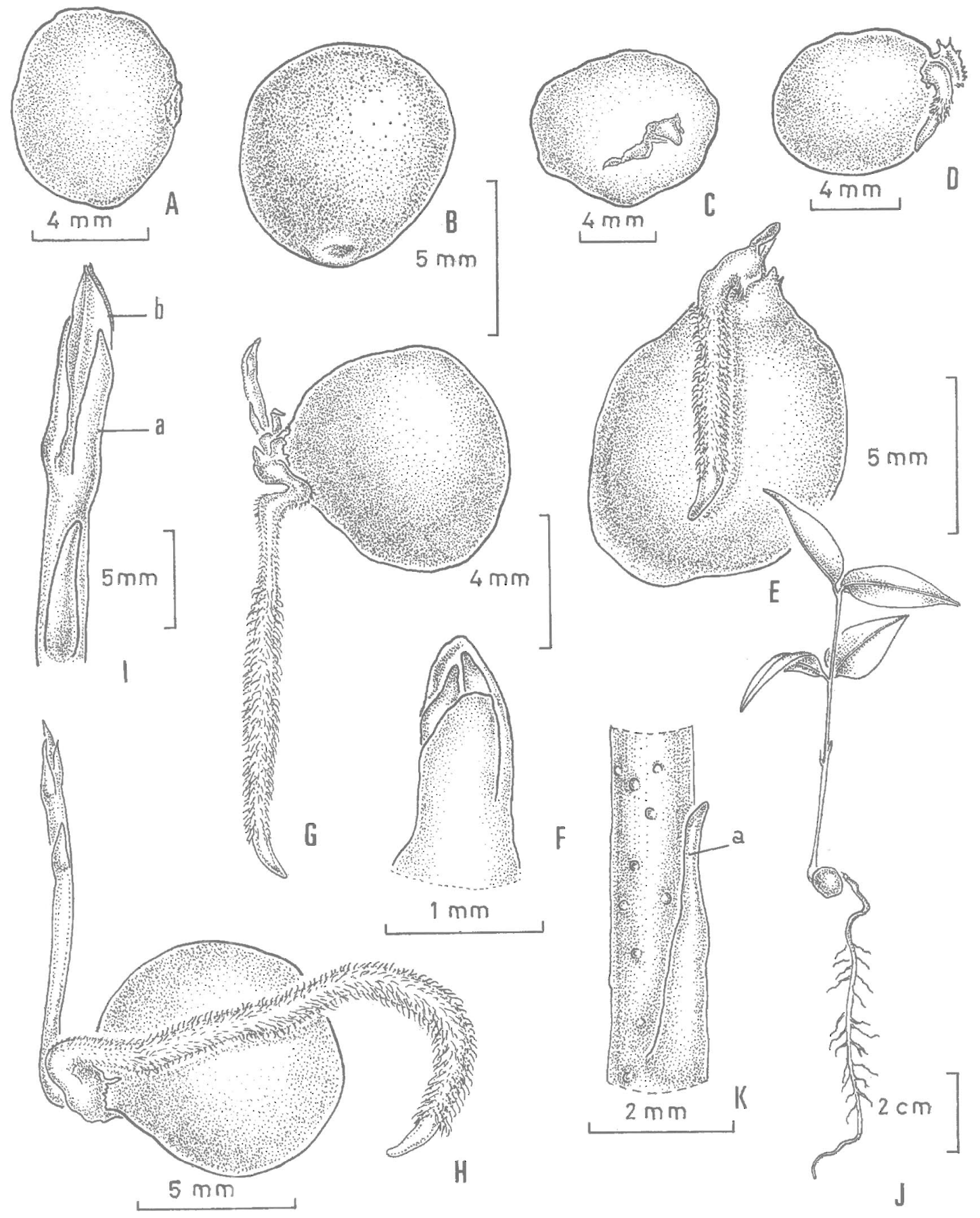

Fig. 2. Eugenia uniflora. A: semilla; B: embrión; C-K: germinación y desarrollo de la plántula; C-F: 3a. semana; F: detalle del epicótilo, cubierto por catafilos; G: 4a. semana;H-I: 5a. semana; I: detalle del epicótilo;J-Ki plántula; K: detalle del epicótilo. a: catafilos, b: nomofilos (Franceschini 13). 
obtuso, en algunos casos retuso, base aguda, margen entero.

\section{Eugenia uniflora (Fig. 2)}

Semilla: 7-9 mm long. x 6-8 mm lat., exendospermada, subglobosa; cubierta seminal delgada, cartácea, blanquecina, lisa, glabra (Fig. 2, A).

Embrión: 7-8 mm long. x 6-7 mm lat. x 4-5 $\mathrm{mm}$ espesor, macizo, globoso, verde oliváceo con pequeños puntos de color granate, glabro; cotiledones reservantes, totalmente soldados formando una sola estructura con el resto del embrión; eje embrionario como una pequeña prominencia (Fig. 2, B).

Germinación y crecimiento: hipogea, fanerocotilar.

3ra. semana: el $8 \%$ de las semillas germinadas; la radícula emerge por el hilo, el epicótilo emerge entre dos catafilos; la plántula mide 6$14 \mathrm{~mm}$ long. (Fig. 2, C-F).

4 ta. semana: $24 \%$ de semillas germinadas; el epicótilo presenta color rojizo (Fig. 2, G).

5ta. semana: entre los dos catafilos aparecen los nomofilos, opuestos, enfrentados por la cara adaxial; la plántula llega a medir desde 2,7-5,3 cm long. (Fig. 2, H-I).

6ta. semana: los nomofilos de color verde claro se vuelven rojizos, mientras que el epicótilo rojizo se torna verde claro.

9na. semana: el primer y segundo par de nomofilos están perfectamente diferenciados.

Plántula (Fig. 2, J y K): glabra; hipocótilo no desarrollado; epicótilo cilíndrico, rojizo, tornánd ose verde durante el crecimiento, con minúsculos puntos glandulares circulares. Catafilos opuestos o alternos, de 1-1,8 mm long., angustiovados, membranáceos, verdes claro con tinte rojizo, ápice agudo a redondeado, margen entero. Nomofilos simples, opuestos a subopuestos; pecíolo 1,5-2 mm long., cóncavo en la cara adaxial y convexo en la abaxial; lámina de 6-25 mm long. x 6-17 mm lat.; ovada, cartácea, glabra, ápice agudo y levemente curvado, base obtusa, margen entero.

\section{Hexachlamys edulis (Fig, 3)}

Semilla: 10-20 mm long. x 15-20 mm lat., exendospermada, globosa, durante la germinación permanece encerrada por el "endocarpo $^{\prime \prime}$ (Fig. 3, A).

Embrión: 11-16 mm long. x 10-16 mm lat., macizo, globoso, alutáceo, glabro; cotiledones reservantes, totalmente soldados y constituyendo la mayor parte del embrión; radícula de 1-3 mm long., cónica (Fig. 3, B).

Germinación y crecimiento: hipogea, criptocotilar; PG $7 \%$.

Se aplicó escarificación mecánica, perforando la estructura leñosa.

1ra. a 3ra. semana: emerge la radícula, llegando a medir 2-20 mm long. (Fig. 3, C).

4ta. semana: germina el $50 \%$ de las semillas.

6ta. semana: emerge el epicótilo, crece hasta $2 \mathrm{~mm}$ long. La plántula llega a medir hasta $42 \mathrm{~mm}$ long.

$7 \mathrm{ma}$. semana: continúa alargándose el epicótilo hasta $10 \mathrm{~mm}$ long. (Fig. 3, D). En algunos casos se observan los primeros catafilos.

8va. semana: aparecen los primeros nomofilos; la plántula mide 9-10 cm long. (Fig. 3, E).

15ta. semana: el cpicótilo alcanza hasta 12 $\mathrm{cm}$ long. y la radícula de 10-12 cm long. y aparecen bien diferenciados desde el 1er. al 3er. par de nomofilos.

Plántula (Fig. 3, F): completamente pubescente, pelos simples; hipocótilo no desarrollado; epicótilo verde claro, cilíndrico. Catafilos alternos, en número de 4-10, 2-4 mm long. x 0,5-1 mm lat., angustiovados, membranáceos, ápice agudo, base obtusa, margen entero. Nomofilos simples, alternos u opuestos; pecíolo acanalado en su cara adaxial; lámina de 1,51,8 cm long. x 0,8-1,2 cm lat., elíptica, cartácea, verde clara, ápice y base agudos, margen entero.

\section{Polygala albicans (Fig. 4)}

Semilla: 4-5 mm long. $x$ 4,5-5,5 mm lat.; exendospermada, globosa; cubierta seminal 

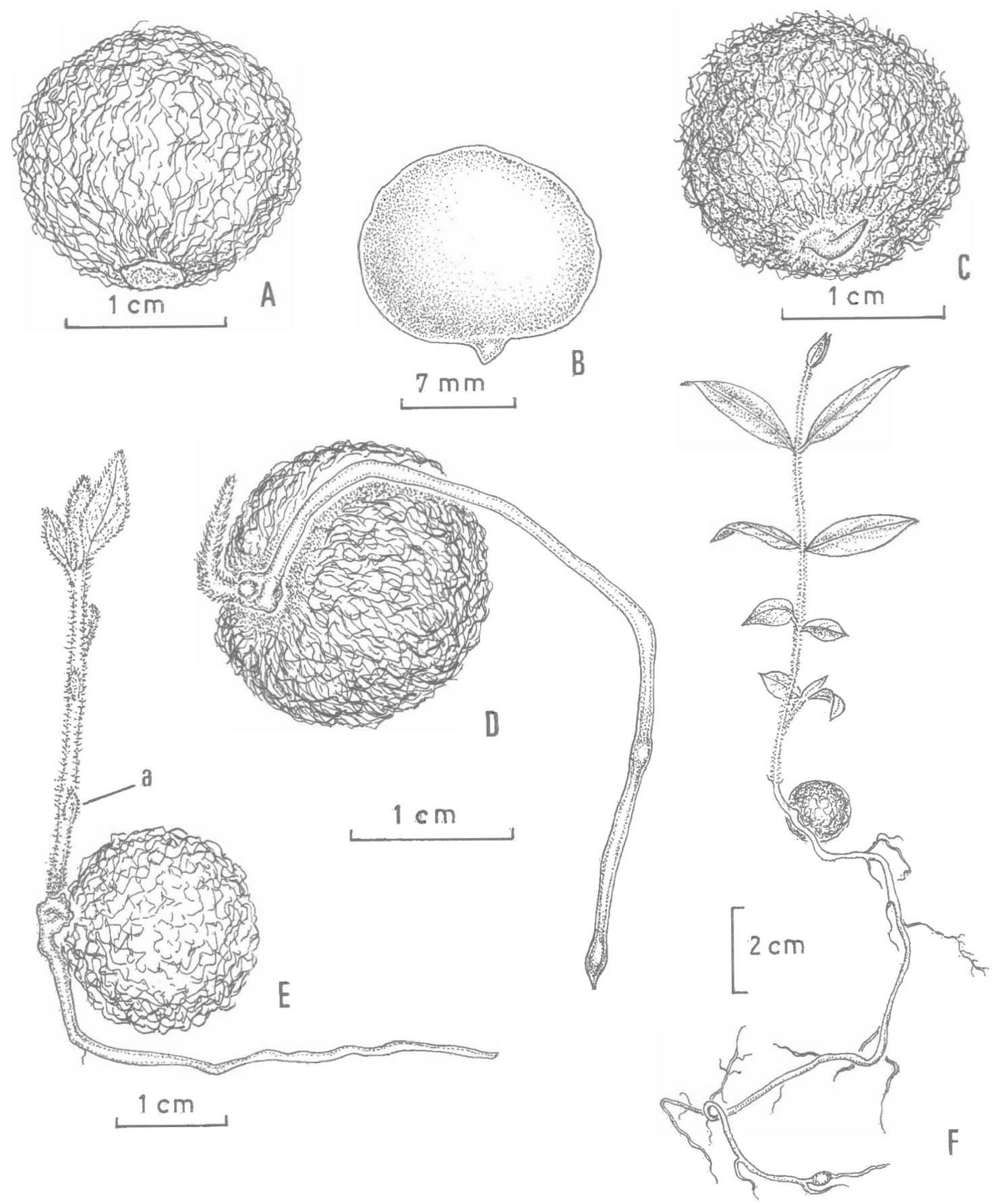

Fig. 3. Hexachlamys edulis. A: semilla; B: embrión; C-F: germinación y desarrollo de la plántula; C: 3a. semana;D:7a. semana; E: 8a. semana; F: plántula. a: catafilo (Franceschini 11). 


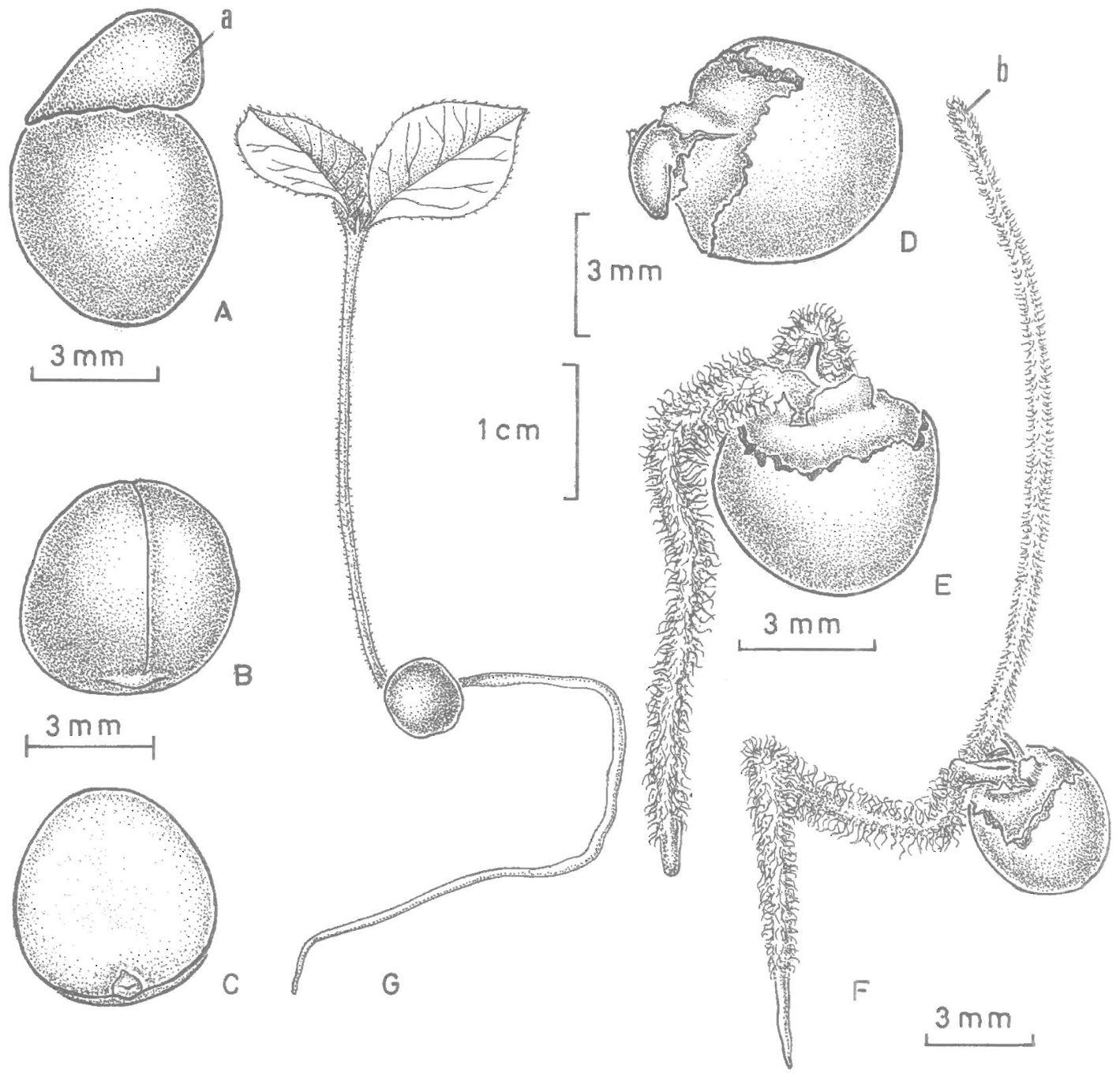

Fig. 4. Polygala albicans, A: semilla; B: embrión; C: eje embrionario y cara interna de un cotiledón; D-G: germinación y desarrollo de la plántula; D: 1a. semana; E: 2a. semana; F: 3a. semana; G: plántula. a: arilo (Franceschini 40).

coriácea, superficie pulida, escasamente pubérula, con pelos simples, castaña negrusca, persistente en la plántula; arilo carnoso, blanco (Fig. 4, A).

Embrión: 4-5 mm long. x 4-4,5 mm lat., globoso, glabro, níveo; eje embrionario $1 \mathrm{~mm}$ long., con la radícula como una diminuta prominencia ubicada en una leve depresión del embrión, plúmula cónica, pequeña, cubierta por los cotiledones; cotiledones reservantes, plano-convexos, carnosos, formando casi la totalidad del embrión (Fig. 4, B y C).

Germinación y crecimiento: hipogea, criptocotilar. PG $6 \%$. Se utilizaron semillas sin arilo.

1ra. semana: la radícula emerge en el lugar donde se encontraba el arilo, llegando a medir hasta $6 \mathrm{~mm}$ long. (Fig. 4, D).

2da. semana: germina el $87 \%$ de las semillas; el epicótilo, en forma de gancho, emerge 
entre los pecíolos de los cotiledones, la radícula con pelos densos y cortos, alcanza hasta 15 mm long. (Fig. 4, E).

3ra. semana: germina el $95 \%$ de las semillas; se alarga el epicótilo hasta $25 \mathrm{~mm}$ long., comienzan a evidenciarse en el ápice los dos primeros nomofilos (Fig. 4, F).

4ta. semana: germina el $100 \%$ de las semi1las; considerable aumento en el tamaño de los los nomofilos; se inicia el despliegue de los mismos. El epicótilo llega a medir hasta $40 \mathrm{~mm}$ long.

5ta. semana: los nomofilos estan completamente desplegados.

$7 \mathrm{ma}$. semana: los nomofilos membranáceos adquieren una consistencia papirácea.

Plántula (Fig. 4, G): pubérula; hipocótilo no desarrollado; epicótilo cilíndrico, muy delgado, castaño. Nomofilos simples, opuestos; pecíolo de 1-1,5 mm long., cilíndrico, pubérulo; lámina de 9-21 mm long. x 6-15 mm lat., elíptica, membranácea al principio, tornándose papirácea, pubérula con pelos uncinulados en la cara abaxial, ápice agudo, base aguda y margen entero, venación pinnada, notoria en toda la superficie de la lámina.

\section{Sapium haematospermun (Fig. 5)}

Semilla: 6-7 mm long. x 5,5-6 mm lat., x 3,5$4 \mathrm{~mm}$ esp; endospermada, biconvexa; cubierta seminal ósea, superficie lisa, negra, totalmente cubierta por un arilo rojo. Endosperma carnoso, jugoso, blanquecino, persistente en los primeros estadios de la germinación. Las pruebas de endosperma dieron positivo al test de Sudán IV para grasas y aceites y negativo al de Lugol para hidratos de carbono (Fig. 5, A).

Embrión: 3,5 mm long. x 2,5 mm lat. axial, foliar, espatulado, blanquecino, glabro; eje embrionario 1,5 mm long. x 0,7 mm lat., cónico levemente engrosado; cotiledones $2 \mathrm{~mm}$ long. x 2,5 mm lat., circulares, delgados, base cordada, margen entero (Fig. 5, B).

Germinación y crecimiento: epigea, fanerocotilar. La germinación se llevó a cabo por escarificación química con ácido sulfúrico, siendo el PG $36 \%$ con ácido durante 60 minutos y $4 \%$ con ácido por 30 minutos. 1ra. semana: la cubierta seminal se rompe en varias partes por la acción del ácido. Se evidencia el endosperma blanquecino; el eje hipocótilo-radícula llega a medir hasta $5 \mathrm{~mm}$ long. (Fig. 5, C).

2da. semana: el hipocótilo se torna rojizo hacia la radícula, llegando a medir $21 \mathrm{~mm}$ long.

3ra. semana: los cotiledones continúan cubiertos por el endosperma, se visualizan los pecíolos y entre éstos la plúmula (Fig. 5, D).

4ta. semana: los cotiledones emergen, enverdecen y se mantienen unidos en el ápice de la lámina por restos de la cubierta seminal; el endosperma persiste como una membrana delgada y castaña; el eje hipocótilo-radícula alcanza a medir hasta $45 \mathrm{~mm}$ long.

5ta. semana: se despliegan los cotiledones; el eje hipocótilo-radícula llega a medir hasta $55 \mathrm{~mm}$ long. (Fig. 5, E).

6ta. semana: aparecen los dos primeros nomofilos y el eje alcanza $65 \mathrm{~mm}$ long. Todo el hipocótilo se torna rojizo.

11va. semana: el hipocótilo se vuelve verde claro y se inicia la caída de los cotiledones.

Plántula: (Fig. 5, F) glabra; látex blanquecino. Hipocótilo glabro, verde claro, cilíndrico. Epicótilo glabro, cilíndrico, rusado, tornándose verde claro cuando aparecen los nomofilos. Cotiledones opuestos, pecíolo de 2-8 mm long., cara adaxial plana, cara abaxial convexa; lámina de 9-12 mm long. x 6,5-10 mm lat., obovada, cartácea a subcarnosa, glabra, de color verde profundo en la cara adaxial y verde claro en la abaxial; ápice obtuso, base aguda, margen entero. Nomofilos simples, opuestos; pecíolo de 1,5-2 mm long., cara adaxial cóncava, cara abaxial convexa; lámina de 10,5-12 mm long. x 4-6 mm lat., lanceolada, herbácea; ápice agudo, base aguda, margen crenàdo, con glándulas en las crenas.

Obs.: se ha observado tricotilia en embriones y en plántulas (Fig. 5, G y H).

\section{Sebastiania brasiliensis (Fig. 6)}

Semilla: 4,5 mm long. x $4 \mathrm{~mm}$ lat.; endospermada, latiobovada; cubierta seminal crustácea, finamente rugosa, parda, con máculas grisáceas a verde oliváceas (Fig. 6, A y 

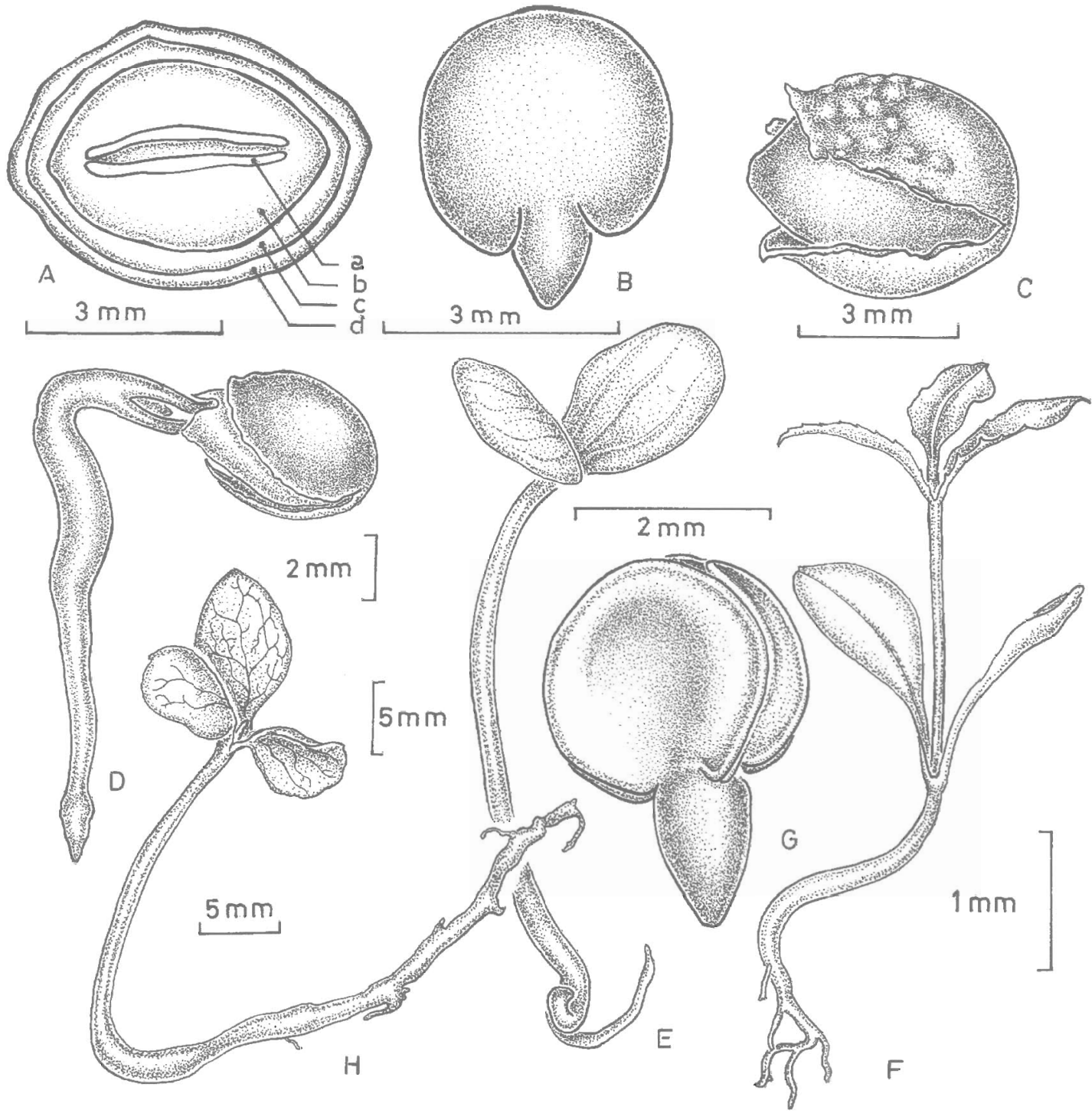

Fig. 5. Sapium haematospermun. A: transcorte de semilla; B: embrión; C-E: germinación y desarrollo de la plántula; C: 1a. semana; D: 3a. semana; E: 5a. semana; F: plántula; G y H: tricotilia; G: embrión; H: plántula. a: embrión, b: endosperma, c: cubierta seminal, d: arilo (Franceschini 22).

B). Endosperma entero, pulposo, ebúrneo, oleaginoso. Las pruebas de endosperma dieron positivo al test de Sudán IV para grasas y aceites y negativo con Lugol para hidratos de carbono.

Embrión: 3 mm long. x 2 mm lat., axial, foliar, espatulado, amarillo pálido, glabro; eje embrionario $1 \mathrm{~mm}$ long.; cotiledones $2 \mathrm{~mm}$ long. x $2 \mathrm{~mm}$ lat., circulares, delgados, ápice obtuso, base cordada, margen entero (Fig. 6, C).

Germinación y crecimiento: epigea, fanerocotilar; PG $63 \%$.

1ra. semana: ruptura de la cubierta seminal por 2 a 3 líneas que parten de la base de la semilla, emergiendo primero la radícula; zona basal de los cotiledones densamente punteada de rojo (Fig. 6, D-E). 

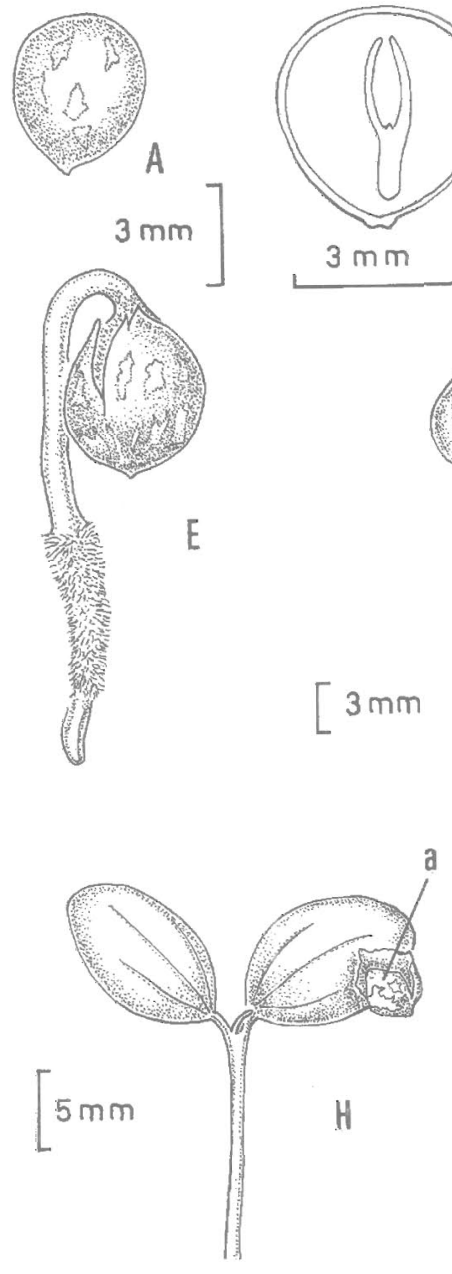

$[3 \mathrm{~mm}$
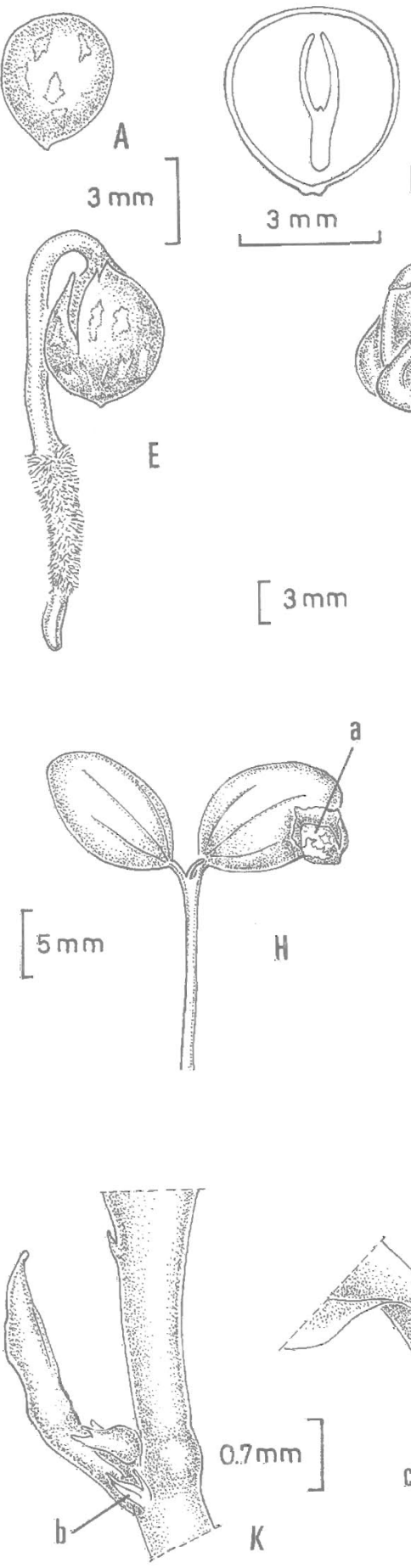

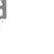

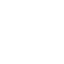
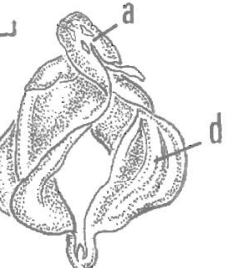

G
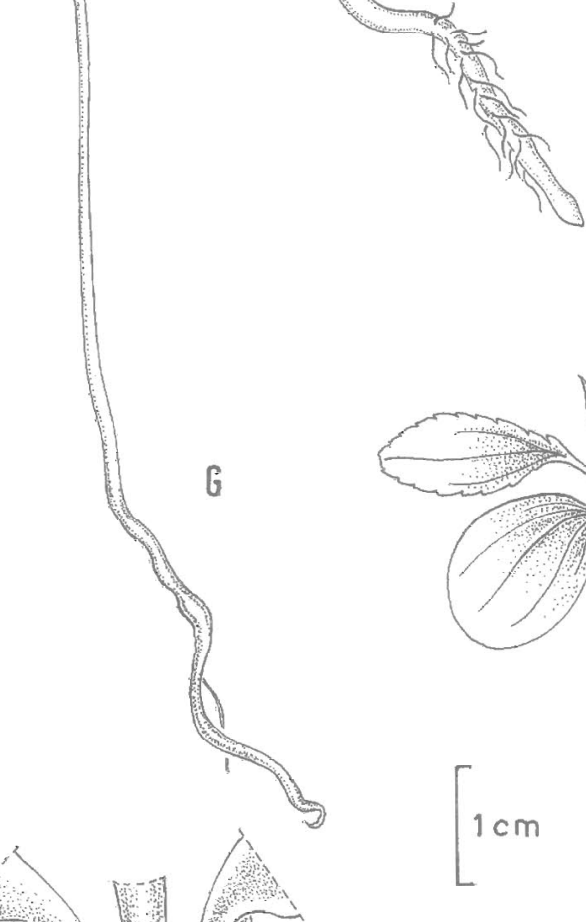

$0.25 \mathrm{~cm}]$
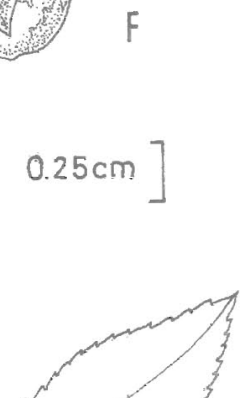
2da. semana: al final de este período el hipocótilo se observa de color verde en la mitad superior y rojiza en la inferior. Zona de transición hipocótilo-radícula castaña (Fig. 6, F).

3ra. semana: al final de este período los cotiledones adquieren un color verde lustroso, permaneciendo unidos apicalmente por la cubierta seminal; persiste una delgada capa de endosperma (Fig. 6, G).

4ta. semana: cotiledones bien desplegados, la cubierta seminal y el endosperma permanecen adheridos al margen de uno de los cotiledones (Fig. 6, H); alargamiento notorio del epicótilo; aparecen los primeros nomofilos.

5ta. - 6ta. semana: se evidencian el tercer y cuarto nomofilo.

Plántula (Fig. 6, I-K): glabra; látex blanco. Hipocótilo y epicótilo cilíndricos, de color verde claro. Cotiledones opuestos, con yemas axilares inconspicuas; pecíolo 1-3 $\mathrm{mm}$ long., cara adaxial levemente acanalada, abaxial convexa; lámina 1,6-2,3 cm long. x 1,4-1,9 cm lat., latielípica a subcircular, cartácea, de color verde oscuro, ápice redondeado, base obtusa, margen entero, venación actinódroma con 3 venas primarias. Catafilos en número de $\overline{2}_{j}$ opuestos, de 1,2-1,3 mm long. x 0,7-1 mm lat., aparecen en el nudo cotiledonar y por alargamiento del epicótilo pueden situarse a $4 \mathrm{~mm}$ del nudo, membranáceos y de color verde esmeralda, luego cartáceos y castaños, ovados, margen crespo. Estípulas de los nomofilos glandulares, subuladas, 0,2-0,5 mm long., de color igual al de los catafilos. Nomofilos simples, alternos; pecíolos 2-3 mm long., cara adaxial levemente acanalada, la abaxial convexa; lámina 2,1-5,9 cm long. x 0,9-2,7 cm lat., elíptica, cartácea; ápice agudo, base aguda, margen crenado, crenas con glándulas rojizas, persistentes.

Obs.: el examen de las semillas no germinadas mostró que el interior estaba totalmente ocupado por una larva de un Himenóptero, Heimbrella rotundigaster Jubba Rao (Eurytomidae), que se alimenta del contenido de la semilla y completa su ciclo de vida en ella.

\section{Discusión y conclusiones}

Chrysophyllum marginatum es característico de los bosques marginales e isletas de bosques del nordeste argentino y comparte el hábitat con C. gonocarpum. Los resultados de los estudios de C. marginatum obtenidos en este trabajo se han comparado con los estudios de C. gonocarpum realizados por Gartland et al. (1990) y Volkart (1995). Los caracteres más importantes para la identificación de las plántulas se presentan en el Cuadro 1.

Las dos especies de Mirtáceas estudiadas, Eugenia uniflora y Hexachlamys edulis, se encuentran incluidas en la tribu Myrteae, subtribu Eugeniinae, caracterizada por poseer embriones con cotiledones fusionados en una masa sólida: tipo "eugenioide" (Landrum \& Stevenson, 1986; Rotman, 1982). Algunos autores (Rotman, 1982; Mattos, 1983) interpretaron la estructura leñosa de Hexachlamys como endocarpo; esta interpretación no ha sido corroborada con estudios anatómicos.

Duke (1969) cita criptocotilia para el género Eugenia, sin embargo en E. uniflora la cubierta seminal se rompe y no permanece cubriendo a los cotiledones en la plántula. Ambas especies

Cuadro 1. Caracteres diferenciales de los embriones y plántulas de Chrysophyllum marginatum y C. gonocarpum

\begin{tabular}{llll}
\hline ESPECIES & EMBRIÓN: & \multicolumn{2}{c}{ PLÁNTULA } \\
& COTILEDONES & Tamaño de los cotiledones & Epicótilo y nomofilos \\
\hline C. gonocarpum & $\begin{array}{l}\text { Nervaduras } \\
\text { notables }\end{array}$ & 27-41 mm long. x 15-21 mm lat. & Glabros \\
C. marginatum & $\begin{array}{l}\text { Nervaduras no } \\
\text { notables }\end{array}$ & $13-14 \mathrm{~mm}$ long. x 0,8-10 mm lat. & Con pelos malpighiáceos \\
\hline
\end{tabular}


tienen germinación hipogea, pero mientras en E. uniflora es fanerocotilar, en $H$. edulis es criptocotilar. Las plántulas se diferencian porque la de E. uniflora es glabra, el epicótilo presenta puntos glandulares notables y los nomofilos son ovados, con el ápice agudo y la base obtusa. La plántula de H. edulis es pubescente, sin puntos glandulares conspicuos en el epicótilo y los nomofilos son elípticos, con la base y el ápice agudos.

Las dos especies de Euforbiáceas se podrían distinguir por los siguientes caracteres: en Sebastiania brasiliensis la lámina de los nomofilos es elíptica y con estípulas glandulares; presenta además yemas axilares cotiledonares y catafilos. Sapium haematospermun presenta nomofilos lanceolados, carece de estípulas, yemas cotiledonares y catafilos.

Polygala albicans es el único representante leñoso de la familia en nuestro país; los caracteres útiles para su identificación son la germinación criptocotilar hipogea, los restos de la cubierta seminal que permanecen en la plántula, el epicótilo castaño y muy delgado y las nervaduras notorias de los nomofilos.

\section{Agradecimientos}

A la Lic. Sara G. Tressens, directora de beca por ser quien orientara mis primeros pasos en la botánica. A la Lic. Adriana Scocchi por su colaboración en la técnicas de germinación. Al Dr. Luis De Santis, de la Universidad Nacional de La Plata, Buenos Aires por la identifica- ción de los Himenópteros. Agradezco asimismo a Laura Simón por el pasado a tinta de los dibujos.

\section{Bibliografía}

BRAVO, L. D. 1978. Estudio comparativo de las plántulas de las subespecies de Cassia aphylla Cav. Darwiniana 21(2-4): 393-399.

D’AMBROGIO DE ARGÜESO, A. 1986. Manual de técnicas en histología vegetal. Ed. Hemisferio Sur S.A. 83 pp.

DIZEO de STRITTMATTER, C. 1973. Nueva técnica de diafanización. Bol. Soc. Argent. Bot. 15 (1): 126-129.

DUKE,J.A. 1969. On tropical tree seedlings. I. Seed, seedlings, systems, and systematics. Ann. Missouri Bot. Gard. 56 (2): 125-161.

GARTLAND, H. M., A.V. BOHREN, D. MUÑOZ y G. F. OTTENWELLER. 1990. Descripción y reconocimiento de las principales especies forestales de la selva misionera en el estado de plántula. Yvyraretá 1(1): 6790.

- 1991. Descripción y reconocimiento de las principales especies forestales de la selva misionera en estado de plántula. Yvyraretá 2 (2): 70-101.

HICKEY, L. J. 1974. Clasificación de la arquitectura de las hojas de Dicotiledóneas. Bol. Soc. Árgent. Bot. 16 (1-2): 1-26.

LANDRUM, L. R. \& D. STEVENSON. 1986. Variability of Embryos in Subtribe Myrtinae (Myrtaceae). Syst. Bot. 11 (1): $155-162$.

MATTOS, J. R. 1983. Myrtaceae do Rio Grande do Sul. Roessléria 5(2): 169-359.

ORFILA, E. N. 1995. Frutos, semillas y plántulas de la flora leñosa argentina. Ediciones Sur, La Plata. 156 pp.

ROTMAN, A. 1982. Los géneros deCalycorectes, Hexachlamys, Myrciaria, Paramyrciaria, Plinia y Siphoneugena en la flora argentina (Myrtaceae). Darwiniana 24 (1-4): 157185.

VOLKART, I. 1995. Chrysophyllum Linn. En: E. N. Orfila (Ed.), Frutos, semillas y plántulas de la flora leñosa argentina. Ediciones Sur, La Plata: 44-47. 